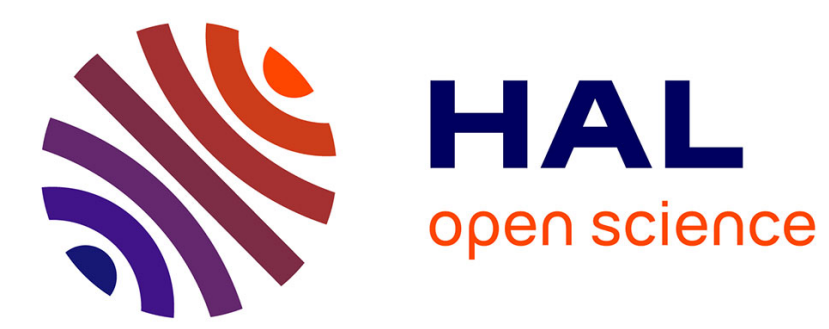

\title{
On the coloration properties of CaF2 : Na
}

\author{
J.M.G. Tijero, J. Casas-González
}

\section{To cite this version:}

J.M.G. Tijero, J. Casas-González. On the coloration properties of CaF2: Na. Journal de Physique Lettres, 1985, 46 (18), pp.861-868. 10.1051/jphyslet:019850046018086100 . jpa-00232910

\section{HAL Id: jpa-00232910 https://hal.science/jpa-00232910}

Submitted on 1 Jan 1985

HAL is a multi-disciplinary open access archive for the deposit and dissemination of scientific research documents, whether they are published or not. The documents may come from teaching and research institutions in France or abroad, or from public or private research centers.
L'archive ouverte pluridisciplinaire HAL, est destinée au dépôt et à la diffusion de documents scientifiques de niveau recherche, publiés ou non, émanant des établissements d'enseignement et de recherche français ou étrangers, des laboratoires publics ou privés. 
Classification

Physics Abstracts

$61.70 \mathrm{D}-78.50$

\title{
On the coloration properties of $\mathrm{CaF}_{2}: \mathrm{Na}$
}

\author{
J. M. G. Tijero (*) and J. Casas-González \\ Departamento de Optica, Facultad de Ciencias, Universidad de Zaragoza, 50009 Zaragoza, Spain
}

(Reçu le 14 mai 1985, accepté le 8 juillet 1985)

\begin{abstract}
Résumé. - Nous avons étudié les propriétés dichrö̈ques et l'existence d'états excités métastables de plusieurs centres colorés créés par irradiation $\mathrm{X}$ dans $\mathrm{CaF}_{2}: \mathrm{Na}$. Selon nos résultats les bandes d'absorption à 600,385 et $322 \mathrm{~nm}$ sont associées au même centre de propriétés optiques orthorhombiques. L'absence d'observation d'un état métastable favorise le modèle du centre $\mathrm{F}_{2 \mathrm{~A}}^{+}$. D'autre part, on prouve aussi que la bande à $500 \mathrm{~nm}$ et une autre absorption à $322 \mathrm{~nm}$ appartiennent au même centre qui a des propriétés optiques tétragonales. Nous avons détecté un état métastable excité de ce centre de durée de vie $0,83 \mathrm{~s}$ à $77 \mathrm{~K}$. Deux modèles possibles sont discutés pour ce centre.
\end{abstract}

\begin{abstract}
We have investigated the dichroic properties and the existence of metastable excited states of several colour centres created by X-irradiation in $\mathrm{CaF}_{2}: \mathrm{Na}$. According to our results absorption bands peaking at 600,385 and $322 \mathrm{~nm}$ are associated to the same centre which behaves optically as orthorhombic. The lack of observation of a metastable state is in favour of the $\mathrm{F}_{2 \mathrm{~A}}^{+}$ model for this centre. On the other hand the band at $500 \mathrm{~nm}$ and another absorption at $322 \mathrm{~nm}$ are proved to belong to the same centre which behaves optically as tetragonal. A metastable excited state of this centre with lifetime of $0,83 \mathrm{~s}$ at $77 \mathrm{~K}$ has been detected. Two possible models are discussed for this centre.
\end{abstract}

\section{Introduction.}

As is well known, $\mathrm{X}$-ray irradiation effects on the optical and magnetic properties of $\mathrm{CaF}_{2}$ are largely modified by the presence of small concentration of impurities. Particularly, the X-ray induced absorption of pure $\mathrm{CaF}_{2}$ and $\mathrm{Na}$ doped $\mathrm{CaF}_{2}$ are wholly different.

$\mathrm{Na}$ impurities enter the $\mathrm{CaF}_{2}$ lattice in a $\mathrm{Ca}^{2+}$ substitutional position as $\mathrm{Na}^{+}$. Local charge compensation is achieved by a $\mathrm{F}^{-}$vacancy in one of the nearest neighbours positions [1]. X-irradiation produces several colour centres depending on the irradiation temperature [2-4]. These centres may also be produced by additive coloration procedures $[5,6]$. One of the interests of the $\mathrm{CaF}_{2}: \mathrm{Na}$ system is its tentative usefulness as colour centre laser material because of the emission properties of one of these centres [7].

It is known that $\mathrm{X}$-irradiation at $77 \mathrm{~K}$ produces two main absorption bands at about 385 and $433 \mathrm{~nm}$. These absorption bands have been identified as due to $F_{A}$ centres $[2,6]$. Other absorption bands at $322,385,500$ and $600 \mathrm{~nm}\left({ }^{1}\right)$ are created by X-irradiation at room tempe-

$\left({ }^{*}\right)$ Present address : C.S.I.C., Instituto de Estructura de la Materia, Serrano, 119, 28006 Madrid, Spain.

( ${ }^{1}$ ) Through this article we will refer to the maxima of these absorption bands when they are measured at $300 \mathrm{~K}$. 
rature. Those at 322, 385 and $600 \mathrm{~nm}$ were early reported by Scouler and Smakula [8]. Rauch [3] ascribed two of them, those at 600 and $385 \mathrm{~nm}$, to a $F_{2 A}$ centre and that at $500 \mathrm{~nm}$ to a $F_{3 \mathrm{~A}}^{+}$ centre. However, M.C.D. experiments carried out recently by Doualan et al. [6] indicated that the centre responsible for the 385 and $600 \mathrm{~nm}$ bands should be a paramagnetic defect. (Following their work we shall call this defect the $\mathrm{Y}$ centre). Thus, they associated these bands to a $\mathrm{F}_{2 \mathrm{~A}}^{+}$ centre and tentatively assigned the $322 \mathrm{~nm}$ band to it, as well. Likewise these authors refused the Rauch's assignation of the $500 \mathrm{~nm}$ band and propose that it could correspond to a $F_{2 \mathrm{~A}}$ centre.

In order to get more information about the origin of the different bands that appear in this compound, we have carried out a series of experiments of polarized bleaching and optical detection of metastable states. Our results indicate that at least two absorption bands have their maxima at about $322 \mathrm{~nm}$, one of them being associated with the 600 and $385 \mathrm{~nm}$ bands and the other with the $500 \mathrm{~nm}$ band.

With regard to the centre responsible of the 322,385 and $600 \mathrm{~nm}$ bands, the $Y$ centre, the absence of detection of a metastable excited state supports the $\mathrm{F}_{2 \mathrm{~A}}^{+}$model. A metastable excited state corresponding to the centre that absorbs at 322 and $500 \mathrm{~nm}$ (the $X$ centre) has been detected. Several experimental results are, apparently, in favour of the $\mathrm{F}_{3 \mathrm{~A}}^{+}$model for this centre.

\section{Experimental.}

The samples used in our experiments were grown by a Bridgman method in our Laboratory. The $\mathrm{Na}$ impurity content of the samples was $1 \mathrm{~mol} \%$ of $\mathrm{NaF}$ in the melt. X-ray coloration was performed either at $77 \mathrm{~K}$ or at $300 \mathrm{~K}$ by a Cu-target X-ray tube operated at $40 \mathrm{kV}$ and $20 \mathrm{~mA}$.

Absorption spectra were measured with a Cary 17 spectrometer in the whole $250-750 \mathrm{~nm}$ range. Optical bleaching experiments were performed with high-pressure $\mathrm{Hg}$ and $\mathrm{Xe}$ lamps. Monochromator and colour filters were used to select the desired wavelengths. Polarized light used in dichroism experiments was obtained with Glan-Thompson Quartz prisms.

In the detection of transient transmittance, light from a $250 \mathrm{~W}$ high-pressure Xe-lamp was used as the exciting light incident upon the crystal at right angles to the measuring beam. The sample was mounted in an Oxford CF-100 continuous flow cryostat. The exciting light was chopped by means of an electromagnetic shutter. Detection was carried out by a photomultiplier RCA C31034. The signal, after amplification was analysed by a HP5480A/B signal analyser obtaining adequate signal-to-noise ratio with several tens of sweeps. Our experimental arrangement can detect transients with time constants larger than $1 \mathrm{~ms}$, this limit being introduced by the shutting time. Data fitting was carried out with an exponential fitting program [9].

\section{Experimental results.}

3.1 OptiCAl ABSORPTION AND DICHROISM. - All the optical dichroism experiments that we report in the present section were performed at $77 \mathrm{~K}$ and both bleaching and measuring light propagated along the [001] direction of the crystals.

When the $\mathrm{CaF}_{2}: \mathrm{Na}$ crystals are exposed to $\mathrm{X}$-irradiation at $77 \mathrm{~K}$, two bands grow at 433 and $387 \mathrm{~nm}$. These bands have been associated, by optical dichroism experiments, to a $F_{A}$ centre [2]. M.C.D. experiments carried out recently by Doualan et al. [6] support this identification. $\mathrm{F}_{\mathrm{A}}$ centres become thermally unstable on warming up to room temperature; the initial absorption spectrum disappears giving rise to a new spectrum (see Fig. 1) consisting of three bands at 600,385 and $322 \mathrm{~nm}$. No band at $500 \mathrm{~nm}$ is formed by this procedure.

We have induced optical dichroism in all these bands by bleaching with $385 \mathrm{~nm}$ light polarized with $\mathbf{E} / /[100]$. The results of this experiment are shown in figure 2 . Dichroism can also be induced in the 385 and $322 \mathrm{~nm}$ bands bleaching with $\mathbf{E} / /[110]$, while in this case no dichroism is induced in the $600 \mathrm{~nm}$ band (see Fig. 3). Analogous results were obtained bleaching with 


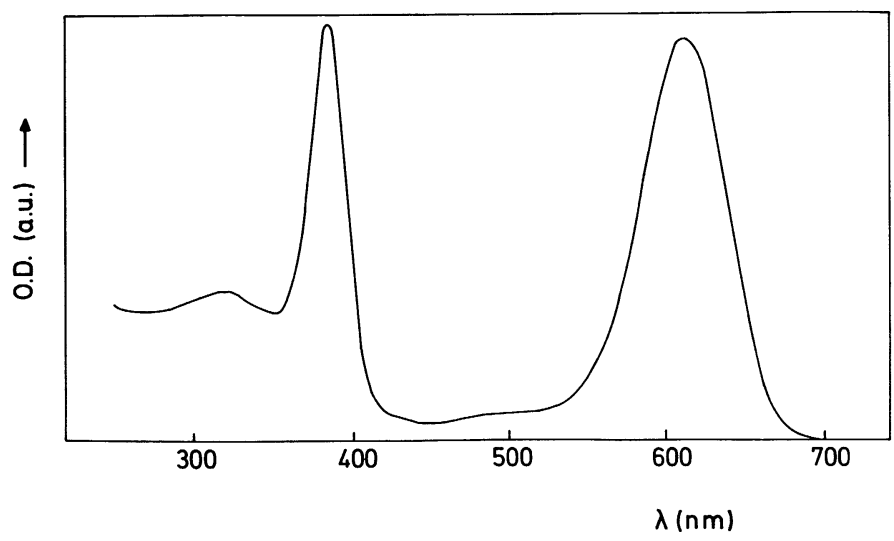

Fig. 1. - Absorption spectrum measured at $77 \mathrm{~K}$ of a $77 \mathrm{~K}$ X-irradiated sample subsequently annealed at $300 \mathrm{~K}$.

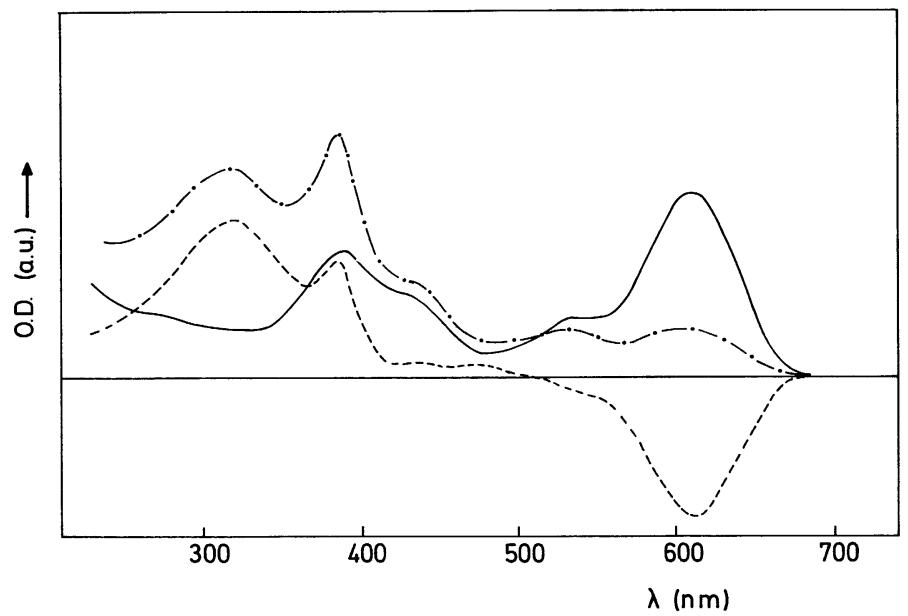

Fig. 2. - Optical dichroism induced with $385 \mathrm{~nm}$ light polarized with $\mathbf{E} / /[100]$. (— $\longrightarrow$ After bleaching, measured with $\mathbf{E} / /[100]$. (-.--) After bleaching, measured with $\mathbf{E} / /[010]$. (- - - ) Resulting dichroism. The absorption at about $440 \mathrm{~nm}$ corresponds to a transition of $F_{A}$ centres created during the bleaching. They have another transition at $380 \mathrm{~nm}$. Their spectrum is not dichroic after a bleaching with polarized light with $\mathbf{E} / /[100]$ and therefore they do not contribute to the observed dichroism. This is not the case when the bleaching light is polarized along the [110] direction. When this happened the spectrum of $F_{A}$ centres was destroyed bleaching with unpolarized light of $\sim 440 \mathrm{~nm}$ (see Figs. 3 and 5).

$322 \mathrm{~nm}$ light, polarized with $\mathbf{E} / /[100]$ and $\mathbf{E} / /[110]$ (see Figs. 4 and 5). The dichroism is thermally destroyed at about $210 \mathrm{~K}$.

In figure 6 we show the absorption spectrum of $\mathrm{CaF}_{2}: \mathrm{Na}$ sample $\mathrm{X}$-irradiated at $300 \mathrm{~K}$. It can be seen that besides the bands that appear by annealing at $300 \mathrm{~K}$ a sample irradiated at $77 \mathrm{~K}$, a band peaking at $500 \mathrm{~nm}$ is formed. On annealing for several minutes at $373 \mathrm{~K}$, the 385 and $600 \mathrm{~nm}$ bands are almost destroyed (and there is a decrease in the optical absorption in the spectral region of about $322 \mathrm{~nm}$ ). Bleaching at $300 \mathrm{~K}$ with $322 \mathrm{~nm}$ light, the spectrum transforms into that shown in figure 1 . When the bleaching is performed at $77 \mathrm{~K}$, no subsequent 


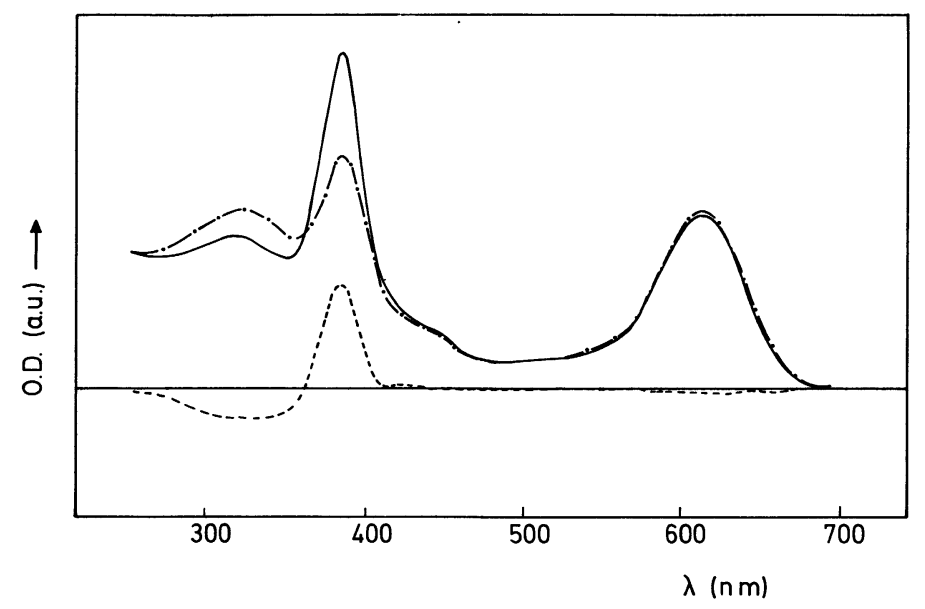

Fig. 3. - Dichroism induced with $385 \mathrm{~nm}$ light polarized with $\mathbf{E} / /[110]$. ( $\longrightarrow$ ) After bleaching, measured with $\mathbf{E} / /[110]$. (-·- -) After bleaching, measured with $\mathbf{E} / /[110]$. (-- - ) Resulting dichroism.

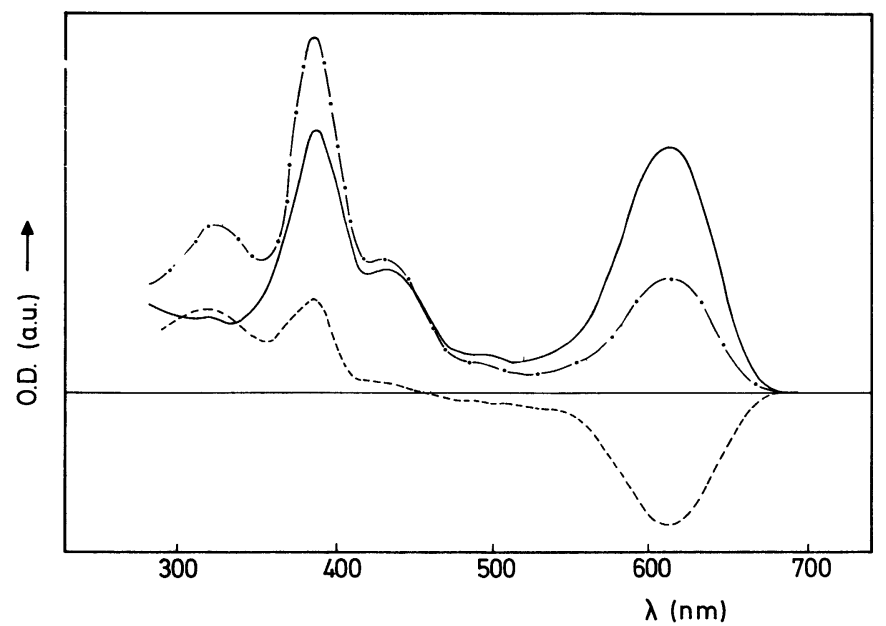

Fig. 4. - Dichroism induced with $322 \mathrm{~nm}$ light polarized with $\mathbf{E} / /[100]$. ( $\longrightarrow$ ) After bleaching, measured with $\mathbf{E} / /[100]$. (----) After bleaching, measured with $\mathbf{E} / /[010]$. (- - - ) Resulting dichroism.

formation of the 385 and $600 \mathrm{~nm}$ band is observed. However the bands are formed by a subsequent annealing up to $300 \mathrm{~K}$.

Dichroism is induced in both 500 and $322 \mathrm{~nm}$ band bleaching with $322 \mathrm{~nm}$ light polarized with $\mathbf{E} / /[100]$. The results of these experiments are given in figure 7 . The dichroism is thermally destroyed at about $260 \mathrm{~K}$. No dichroism can be induced by bleaching with $322 \mathrm{~nm}$ light polarized along the [110] direction.

On the other hand, it is not possible to destroy this spectrum bleaching with $500 \mathrm{~nm}$ light at $77 \mathrm{~K}$. Bleaching at $77 \mathrm{~K}$ with light of $500 \mathrm{~nm}$ polarized either [100] or [110] does not induce any polarization in the absorption spectrum.

3.2 TRANSIENT TRANSMITTANCE EXPERIMENTS. - It is well known that the $\mathrm{F}_{2}$ centre in $\mathrm{CaF}_{2}$ and $\mathrm{SrF}_{2}$ has a spin triplet state a few tenths of electron-volts above the ground state [10]. The 


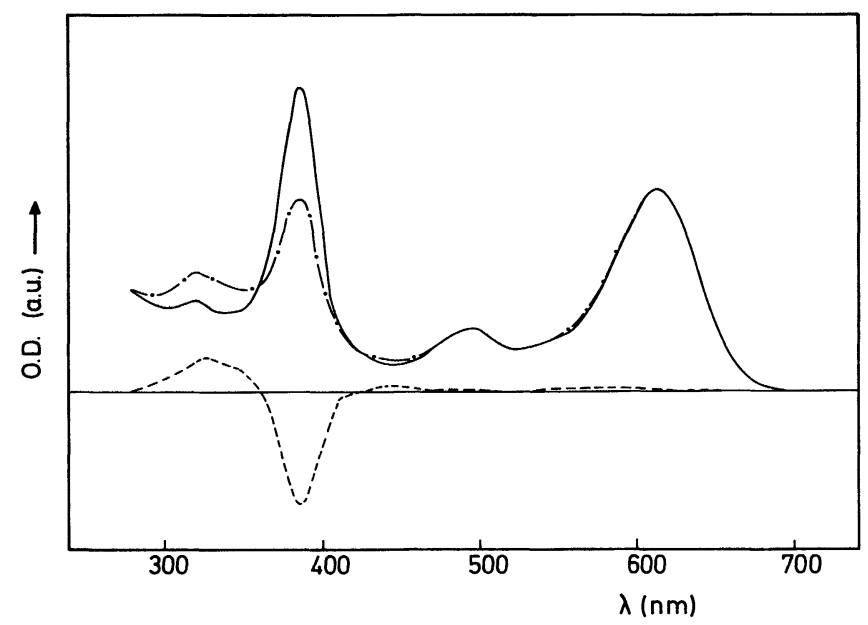

Fig. 5. - Dichroism induced with $322 \mathrm{~nm}$ light polarized with $\mathbf{E} / /[110]$. ( $\longrightarrow$ ) After bleaching, measured with $\mathbf{E} / /[110]$. (-.--) After bleaching, measured with $\mathbf{E} / /[110]$. (-- - ) Resulting dichroism.

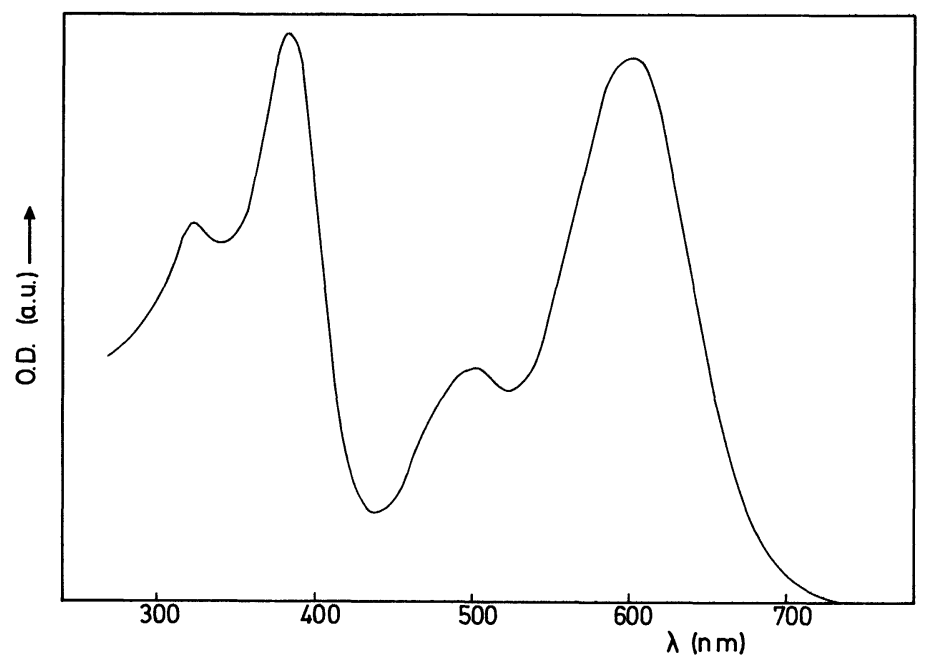

Fig. 6. - Absorption spectrum of a sample of $\mathrm{CaF}_{2}: \mathrm{Na}$ irradiated at $300 \mathrm{~K}$. Measured at $300 \mathrm{~K}$.

presence of this state has been observed by the detection of transient effects, induced by optical pumping, in the transmittance. Transients arise by depopulation (pumping light induced) and subsequent repopulation of the ground state in the assembly of centres. In some cases, optical population of this metastable state allows the detection of paramagnetic resonance associated to it. Characteristic relaxation times of the transients are rather long. (In $\mathrm{CaF}_{2}$, where most of the $F_{2}$ centres are $\langle 100\rangle$ type it was found a lifetime of $1.7 \mathrm{~s}$ at $77 \mathrm{~K}$ for the recovery of the $M$ band. See Ref. [10] for other references.)

We have used this technique to detect the existence of metastable states in the centres responsible for the different absorption spectra in $\mathrm{X}$-irradiated $\mathrm{CaF}_{2}: \mathrm{Na}$ and we have obtained the following results : 


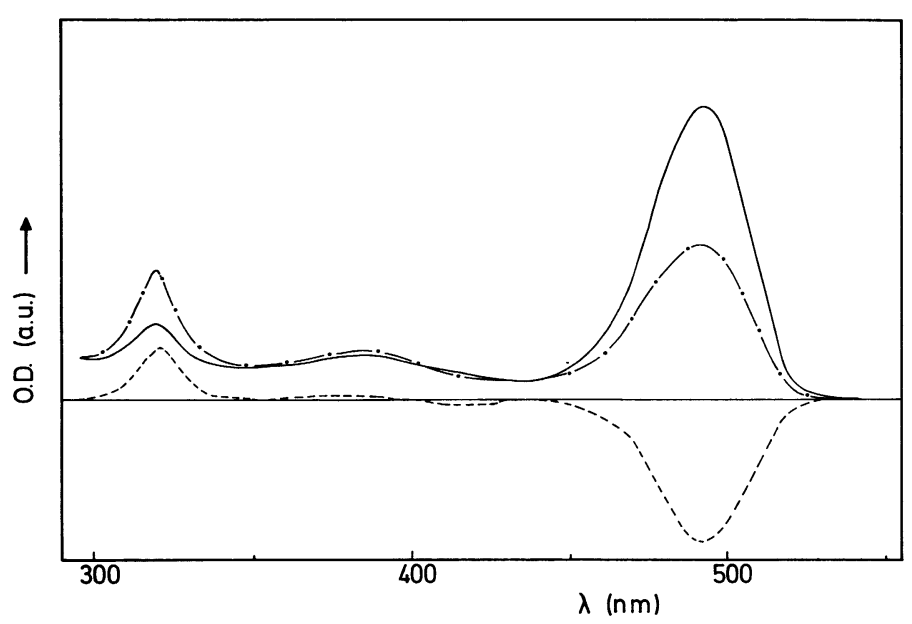

Fig. 7. - Dichroism induced in the absorption spectrum of the $\mathrm{X}$ centres bleaching with $322 \mathrm{~nm}$ light polarized with $\mathbf{E} / /[100]$. (— $\longrightarrow$ After bleaching, measured with $\mathbf{E} / /[100]$. (-.--) After bleaching, measured with $\mathbf{E} / /[010]$. (--- ) Resulting dichroism. The band at $390 \mathrm{~nm}$ grows during the bleaching with $322 \mathrm{~nm}$ light. (See below.)
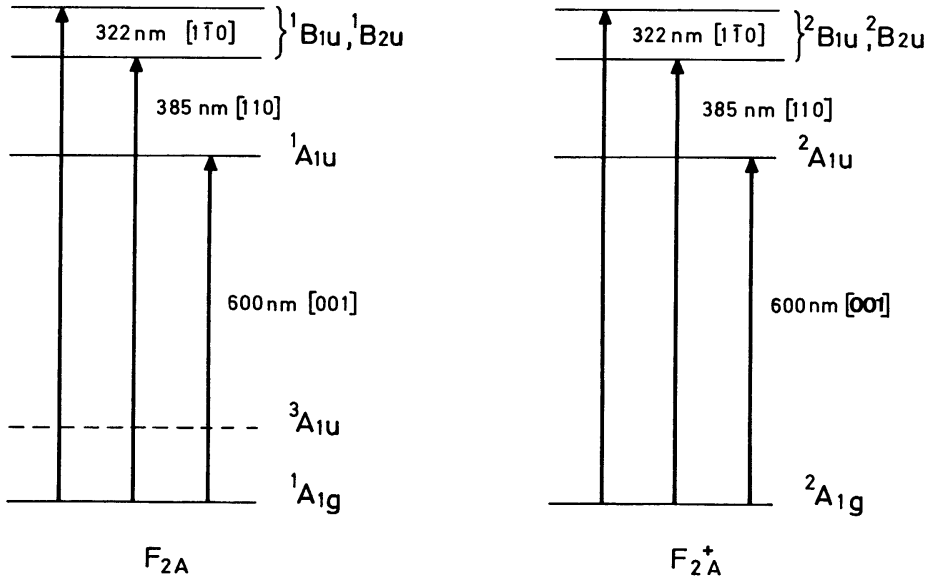

Fig. 8. - Energy level diagram for the $\mathrm{F}_{2 \mathrm{~A}}$ and $\mathrm{F}_{2 \mathrm{~A}}^{+}$centres according to our dichroism experiments. The optical transitions and the corresponding polarizations are indicated as well. Our results do not allow to distinguish the relative positions of the $B_{1 u}$ and $B_{2 u}$ levels.

a) In a sample with the absorption spectrum of figure 1, we have investigated the transmittance in $600 \mathrm{~nm}$ and $385 \mathrm{~nm}$ at $77 \mathrm{~K}$ pumping with light in the $600 \mathrm{~nm}$ band. In all cases we did not observe any transient with relaxation time longer than $1 \mathrm{~ms}$.

b) In a sample with the spectrum of figure 6, pumping with light in the $500 \mathrm{~nm}$ band, we observed a transient in the transmittance of $500 \mathrm{~nm}$. Its relaxation time is $\tau=0.83 \pm 0.08 \mathrm{~s}$ at $77 \mathrm{~K}$. 


\section{Discussion.}

4.1 The Bands AT 600, 385 AND $322 \mathrm{~nm}$. - The dichroism experiments carried out in the spectrum of figure 1 indicate clearly that the 600,385 and a band at $322 \mathrm{~nm}$ belong to the same centre. This confirms the suggestions made by Doualan et al. [6] on the basis of their M.C.D. experiments. Furthermore our dichroism experiments also show that the centre is not optically axial, the transition corresponding to the $600 \mathrm{~nm}$ band must be polarized along the $\langle 100\rangle$ directions and those at 385 and $322 \mathrm{~nm}$ must be polarized along $\langle 110\rangle$ direction mutually perpendicular and perpendicular to the polarization of the $600 \mathrm{~nm}$ transition.

These results are in opposition to the conclusions of the work carried out by Rauch [3] using the polarized luminescence method.

Two models have been proposed for the centre responsible of the 600 and $385 \mathrm{~nm}$ bands, the $\mathrm{Y}$ centre, which according to our results must have another transition at $322 \mathrm{~nm}$. Rauch [3] ascribed it to a $\mathrm{F}_{2 \mathrm{~A}}$ centre (a $\mathrm{F}_{2}$ centre close to a $\mathrm{Na}^{+}$impurity). Doualan et al. [6] propose the model of a $\mathrm{F}_{2 \mathrm{~A}}^{+}$centre in view of their M.C.D. experiments. Our dichroism experiments do not allow to decide between these two models. Both are compatible with the observed results.

In figure 8 we show an energy level schema for both centres with the corresponding transitions according to the dichroism results. We have labelled the energy levels assuming that the point symmetry group of the defect is $\mathrm{D}_{2 \mathrm{~h}}$ with the main binary axis along the molecular axis. In fact the pure geometrical symmetry is lower $\left(\mathrm{C}_{2 \mathrm{~V}}\right)$ and the binary axis is along the $\mathrm{Ca}^{2+}-\mathrm{Na}^{+}$ line. However, if we label the energy levels according to the $\mathrm{C}_{2 \mathrm{v}}$ group with the quantization axis along the $\mathrm{Ca}^{2+}-\mathrm{Na}^{+}$line, the observed polarizations of the transitions do not agree with those expected. So we have to conclude that the quantization axis is along the line joining the vacancies and the centre exhibits $\mathrm{D}_{2 \mathrm{~h}}$ symmetry, although there is no geometrical invariance under a rotation of $180^{\circ}$ around the axis joining the vacancies.

Our transient transmittance experiments are in favour of the $\mathrm{F}_{2 \mathrm{~A}}^{+}$centre model, since this centre does not own any metastable state. Unfortunately, the experimental results are not fully conclusive. It could happen that the relaxation time for the $F_{2 A}$ centre would be beyond our detection ability (shorter than $1 \mathrm{~ms}$ ). This is possible although it does not seem very likely that the relaxation time of a perturbed $\mathrm{F}_{2}$ centre may be three orders of magnitude shorter than the unperturbed centre.

Very recently, Rauch [11] has investigated the effect of bleaching at $77 \mathrm{~K}$ with $385 \mathrm{~nm}$ light the spectrum of figure 1. According to his results, during this bleaching a new centre is formed with absorption bands at 440 and $325 \mathrm{~nm}$, its emission (peaking at $635 \mathrm{~nm}$ ) being polarized along the $\langle 100\rangle$ directions. He argues that this spectrum should belong to a $\mathrm{F}_{2 \mathrm{~A}}^{+}$centre, produced by ionization of what he assumes are $\mathrm{F}_{2 \mathrm{~A}}$ centres. His results, however can be better interpreted assuming that this new centre is in fact a $\mathrm{F}_{2 \mathrm{~A}}$ centre created by trapping at a $\mathrm{F}_{2 \mathrm{~A}}^{+}$ centre an electron released from another $\mathrm{F}_{2 \mathrm{~A}}^{+}$centre. This mechanism would explain his experimental results, mainly the point that cannot be fully understood with his model : the new centres are created randomly oriented across all the space directions.

Moreover, this interpretation accounts for the other experimental results (low temperature $\mathrm{X}$-irradiation, dichroism, growth of the concentration of the $\mathrm{Y}$ centre during the thermal decay of these new centres).

4.2 The BANDS AT 500 AND $322 \mathrm{~nm}$. - When a crystal X-irradiated at R.T. is annealed at $\sim 370 \mathrm{~K}$, two bands peaking at 500 and $322 \mathrm{~nm}$ remain. Our dichroism experiments show that these bands must belong to the same centre. Consequently, when a $\mathrm{CaF}_{2}: \mathrm{Na}$ crystal is irradiated at R.T., two bands belonging to different centres grow at $322 \mathrm{~nm}$. Our results also demonstrate that the centre behaves optically as if it were axial with a four-fold axis along the $\langle 100\rangle$ directions, one transition being $\pi$ type and the other one $\sigma$ type. The experiments do not allow to distinguish the character of each band. 
Again, two different models have been proposed for this centre (the $X$ centre). Rauch [3] and Arkhangelskaya and Shcheulin [5] propose a linear $\mathrm{F}_{3 \mathrm{~A}}^{+}$centre in view of their results of polarization luminescence. Doualan et al. [6] tentatively propose a $\mathrm{F}_{2 \mathrm{~A}}$ centre.

Both models are compatible with our dichroism results again. On the other hand, the observation of a metastable excited state cannot decide between these two models, provided that both should have such a state. (This result, however, leaves out other possibilities such as a $\mathrm{F}_{2 \mathrm{~A}}^{+}$or a $\mathrm{F}_{3 \mathrm{~A}}^{2+}$ centre.)

However, there are other results that may be in favour of the linear $\mathrm{F}_{3 \mathrm{~A}}^{+}$model : if we bleach at $77 \mathrm{~K}$ a sample containing $X$ centres with $322 \mathrm{~nm}$ light, a new band peaking at $390 \mathrm{~nm}$ grows during the destruction of the $\mathrm{X}$ centres. (See Fig. 7.)

Heating the sample up to $300 \mathrm{~K}$, the spectrum corresponding to the $\mathrm{Y}$ centres is formed. If the $\mathrm{X}$ centre were a $\mathrm{F}_{2 \mathrm{~A}}$ centre, we would expect the formation of $\mathrm{F}_{2 \mathrm{~A}}^{+}$centres if the $\mathrm{F}_{2 \mathrm{~A}}$ centre were ionized during the bleaching. If the centre were dissociated the formation of $F$ and $F_{A}$ centres could be expected. In fact, we do not observe any of these results. The band that grows at $390 \mathrm{~nm}$ could be assigned to $\mathrm{F}_{3 \mathrm{~A}}^{2+}$ centres formed by ionization of $\mathrm{F}_{3 \mathrm{~A}}^{+}$centres, although there are other possibilities.

On the other hand, as we have already discussed, the results of Rauch in the study of the photobleaching of $Y$ centres at $77 \mathrm{~K}$ could be interpreted assuming the formation of $F_{2 A}$ centres, that would absorb at 440 and $325 \mathrm{~nm}$.

\section{Acknowledgments.}

The authors are indebted to Prof. R. Alcalá for many helpful discussions during the course of this investigation. We also want to thank Dr. J. Tornos for his aid in the lifetime measurements.

\section{References}

[1] Nowick, A. S., in Point defects in Solids, J. H. Crawford and L. M. Slifkin, eds (Plenum Press, New York) 1976, vol. 1, chapter 3 and references within.

[2] Lisitsyn, V. M. and Shtanko, V. F., Opt. Spectrosc. 42 (1977) 433.

[3] RaUCH, R., Izv. Akad. Nauk. S.S.S.R., Ser. Fiz. 37 (1973) 595.

[4] Arkhangelskaya, V. A., Fedorov, A. A. and Feofilov, P. P., Opt. Spectrosc. 44 (1978) 240.

[5] Arkhangelskaya, V. A. and Shcheulin, A. S., Opt. Spectrosc. 50 (1981) 629.

[6] Doualan, J. L., Margerie, J., Martin-Brunetière, F. and Rzepka, E., J. Physique Lett. 44 (1983) L-375.

[7] Arkhangelskaya, V. A., Fedorov, A. A. and Feofilov, P. P., Opt. Commun. 28 (1979) 37.

[8] Scouler, W. J. and Smakula, A., Phys. Rev. 120 (1960) 1154.

[9] Bernabeu, E. and Pelayo, J., Rev. Acad. Ciencias Zaragoza 35 (1980) 59.

[10] Hayes, W. and Stoneham, A. M., in Crystals with the Fluorite Structure, W. Hayes., ed. (Oxford University Press) 1974, chapter 4 and references within.

[11] RaUCH, R., Phys. Status Solidi (b) 123 (1984) 93. 